\title{
Spectre of contamination
}

\section{London}

NEw evidence has emerged that the CBL1 virus isolate used to develop one of the first commercial diagnostic blood tests for HIV infection may in fact have arisen from laboratory contamination of a cell culture with LAV-1 or HTLV-IIIB - the HIV isolates discovered respectively by Luc Montagnier at the Pasteur Institute in Paris in 1983 and by US National Institutes of Health researcher Robert Gallo in 1984.

The commercial implications of the discovery are not yet clear - a European patent has not yet been issued for LAV-1. But the possibility of laboratory crosscontamination, in one of the most respected HIV research laboratories, underlines a serious general problem with cell culture contamination that has been a hazard since the early days of AIDS research in the mid-1980s.

Amino acid sequence analysis shows that CBL1 is remarkably similar to both LAV-1 and HTLV-IIIB. Given that both viruses were being cultured in his laboratory, Robin Weiss, from the Institute of Cancer Research in London, cannot rule out the possibility that a cell-culture used to grow HIV isolated from a London patient in 1984 became contaminated with LAV-1 or HTLV-IIIB (see Scientific Correspondence, page 374 ).

Gerald Myers, who runs an international database of HIV sequences at the Los Alamos National Laboratory, says that nucleotide sequences diverging by as little as three per cent at variable regions of the env gene almost certainly indicate that the isolate came from the same patient. Slightly more divergence, typically 3 to 7 per cent, is found between 'epidemiologically-linked' cases, such as HIV-positive mothers and their infected babies. Genuinely unlinked isolates usually diverge by much more than 10 per cent at the env gene.

The new sequence data for CBL1 are for amino acid sequences coded by env and two other variable genes, so do not correspond precisely to Myers' data. Overall, these sequences diverge by only about 2 per cent from those of LAV-1 and HTLV-IIIB. Peter Highfield, head of molecular biology at Wellcome Diagnostics, which markets the UK HIV test, says the divergence between the isolates at the nucleotide level will be similarly low.

CBL.1 is the latest in a line of virus isolates that have been found to be remarkably similar to LAV-1, suggesting that they arose from laboratory crosscontamination. The similarity between LAV-1 and Gallo's HTLV-IIIB is the most celebrated, sparking the accusation that Gallo had 'stolen' Montagnier's virus - dismissed in a subsequent NIH investi- gation (see Nature 347, 603; 1990). Genetic sequences from two isolates, published in the Journal of Virology last year, which were thought to be from separate patients in New York and Nebraska, show they are also very similar to LAV-1 (see Nature 347, 3 \& 18; 1990).

Contamination of cell cultures with macaque simian immunodeficiency virus (SIV) in the laboratory of Myron Essex at Harvard is also now accepted as the probable origin of isolates originaliy described as STLV-III ${ }_{A \mathrm{AM}}$ from an African green monkey and HTLV-IV, from a woman in West Africa (see Nature 331, 562; 1988).

The precise route of cell culture contamination in these cases is not known contamination via glassware is one pos- sibility, or by virus particles in aerosol droplets entering the atmosphere of hoods used to manipulate cultures. Because viruses tend to adapt to cell culture after repeated generations in the laboratory, even small amounts of a contaminating virus can out-compete a new isolate and come to dominate a culture.

Simon Wain-Hobson, from the Pasteur Institute, says that the contamination problem should not be seen as professional failure on the part of AIDS researchers, rather as an "occupational hazard". Other areas of virology have been similarly afflicted, he says. The research climate in AIDS laboratories in the mid1980 s should also be borne in mind, according to Wain-Hobson - producing new HIV isolates was a high priority, to "get a handle" on AIDS.

Peter Aldhous

\section{Allocation pleases no-one}

\section{London}

All five British research councils say that they must postpone planned research projects, because of the disappointingly low UK science budget, which was divided between the research councils last week

The Medical Research Council (MRC) seems to have fared best in this year's shareout (see table), announced by Secretary of State for Education and Science Kenneth Clarke. But Nick Winterton, head of the MRC secretariat, says that $£ 4.1$ million of that money is earmarked to begin restructuring British clinical research. The plan is to close the MRC Clinical Research Centre at Northwick Park Hospital in North London in 1994, establish a new centre at the Royal Postgraduate Medical School in London, and improve clincal research at a number of other UK teaching hospitals.

RESEARCH COUNCIL BUDGETS ( $£$ million)

Agricultural and Food

Economic and Social

Medical

Natural Environment 1991-92 1990-91 93 35 200

Science and Engineering

85 36

185

135 438

\section{$£ 15$ million goes to the Royal Society}

Leaving this money aside, the MRC is left with an increase of only 5.8 per cent over last year's allocation, lower than the current rate of inflation. New research into neurodegenerative diseases, diabetes and molecular genetics will be postponed, Winterton says, and spending in the MRC's existing research units and on research grants will fall, unless inflation drops rapidly.

The Science and Engineering Research Council (SERC)'s budget crisis (see Nature 347, 377; 29 November 1990) will not be eased by its allocation for 1991-92, described as "lousy" by SERC chairman Sir Mark Richmond. On 6 February, SERC's governing council will produce a detailed package of spending cuts, postponing several large new projects and cutting back existing research.

The other three research councils are not planning cutbacks in their existing programmes this year, but are shelving some new research. The Agricultural and Food Research Council says that a joint clean technology initiative with SERC (see Nature 346, 691; 23 August 1990) will be restricted to a "modest start", and research on the biological impact of global environmental change must be delayed.

The Natural Environment Research Council (NERC)'s allocation is less than last year's, but much of the 1990-91 spending was earmarked for the Antarctic research ship James Clark Ross. NERC secretary Eileen Buttle says the NERC is now in the "eye of a storm", and will be forced to cut back if more money is not available next year.

The Economic and Social Research Council says that new research into global environmental change and the evolving economic and social climate of Eastern Europe will go ahead, but the number of new projects will be smaller than hoped.

Traditionally, the detailed advice on the allocation of the science budget given by the Advisory Board for the Research Councils (ABRC) to the Secretary of State has been released with the research councils' budgets. But that openness - a rare blemish in the strict policy of secrecy over the British public expenditure process - has been discontinued. In a terse statement, Clarke simply said he had followed the ABRC's advice.

Peter Aldhous 